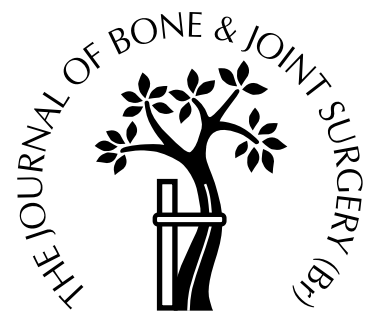

\title{
Tibiofemoral movement 3: full flexion in the living knee studied by MRI
}

\author{
S. Nakagawa, Y. Kadoya, S. Todo, A. Kobayashi, H. Sakamoto, \\ M. A. R. Freeman, Y. Yamano \\ From Osaka City University and the Sakamoto Orthopaedic Clinic, Osaka, Japan
}

W e studied active flexion from $90^{\circ}$ to $133^{\circ}$ and passive flexion to $162^{\circ}$ using MRI in 20 unloaded knees in Japanese subjects. Flexion over this arc is accompanied by backward movement of the medial femoral condyle of $4.0 \mathrm{~mm}$ and by backward movement laterally of $15 \mathrm{~mm}$, i.e., by internal rotation of the tibia. At $162^{\circ}$ the lateral femoral condyle lies posterior to the tibia.

J Bone Joint Surg [Br] 2000;82-B:1199-200.

Received 29 October 1999; Accepted 7 January 2000

In previous reports we and others have examined the relative movement of the tibia and femur in the living unloaded knee during flexion to $90^{\circ}$ and $120^{\circ}$ using MRI. ${ }^{1,2}$ We have now extended this investigation to the limits of active flexion $\left(133^{\circ}\right)$ and of passive flexion $\left(162^{\circ}\right)$. This study has been based on the knee in Japanese subjects since a position of full passive flexion is used in everyday life in Japan.

\section{Subjects and Methods}

The subjects were 20 adult male volunteers without symptoms in their knees and with normal MR images. Their mean age was 29.7 years (26 to 40 ).

The left knee was scanned in an open MR imaging unit (Airis; Hitachi, Tokyo, Japan). The knees were imaged in neutral rotation at $90^{\circ}$, in active maximum flexion and in passive maximum flexion. Measurements were made as described elsewhere. ${ }^{3}$ At $90^{\circ}$ flexion and active maximum flexion, the subject was scanned while lying on his side with the knee to be imaged in contact with the table. The position of maximum passive flexion was maintained by the body-weight (Fig. 1). At this position little tibial rotation was possible, i.e. the knee was rotationally locked.

S. Nakagawa, MD, Orthopaedic Surgeon

S. Nakagawa, MD, Orthopaedic
Y. Kadoya, MD, PhD, Lecturer

A. Kobayashi, MD, PhD, Assistant Professor

Y. Yamano, MD, PhD, Professor

Department of Orthopaedic Surgery, Osaka City University Medical School, 1-4-3

Asahimachi Abeno-ku, Osaka City 545-5858, Japan.

S. Todo, MD, PhD, Research Fellow

London Hospital Medical College

H. Sakamoto, MD, $\mathrm{PhD}$

Sakamoto Orthopaedic Clinic, Sakai City, Osaka, Japan

M. A. R. Freeman, MD, FRCS, Honorary Consultant Orthopaedic Surgeon

The Bone and Joint Research Unit, The Royal London Hospital, Whitechapel Road, London E1 1BB, UK.

Correspondence should be sent to Dr Y. Kadoya or Mr M.A.R. Freeman.

(C)2000 British Editorial Society of Bone and Joint Surgery

0301-620X/00/810718 \$2.00

VOL. 82-B, No. 8, NOVEMBER 2000

\section{Results}

From $90^{\circ}$ to full active flexion $\left(133 \pm 9^{\circ}\right.$, mean $\left.\pm \mathrm{SD}\right)$ the mean posterior translation of the lateral femoral condyle was $13 \pm 6 \mathrm{~mm}$ whereas for the medial femoral condyle it was $2 \pm 2 \mathrm{~mm}$. Therefore, over this arc of flexion, a mean tibial internal rotation of $15 \pm 9^{\circ}$ occurred around an axis passing through the medial tibial condyle.

Passively forcing the knee from active to full passive flexion (i.e., from $133^{\circ}$ to $162 \pm 4^{\circ}$, mean $\pm \mathrm{SD}$ ) moved the medial femoral condyle back a further $4.5 \pm 2 \mathrm{~mm}$ and the lateral femoral condyle $15 \pm 4 \mathrm{~mm}$. Thus there was a further $13 \pm 6^{\circ}$ of internal tibial rotation combined with about $4.0 \mathrm{~mm}$ of femoral posterior translation. At full passive flexion, the centre of the posterior circular portion of the lateral femoral condyle was $7 \pm 5 \mathrm{~mm}$ posterior to the posterior tibial cortex and the lateral femoral condyle was only just in contact with the lateral tibial condyle. The medial femoral condyle had lifted away from the tibia.

Representative MRIs, confirmatory cryosections of the medial and lateral compartments in Caucasian knees in full flexion, and the displacements of the condyles with flexion from their position at $90^{\circ}$ are shown in Figures 2, 3 and 4.

\section{Conclusions}

Previous studies ${ }^{1,2,3}$ have shown that as the unloaded knee is flexed to $120^{\circ}$ in neutral rotation, the lateral femoral

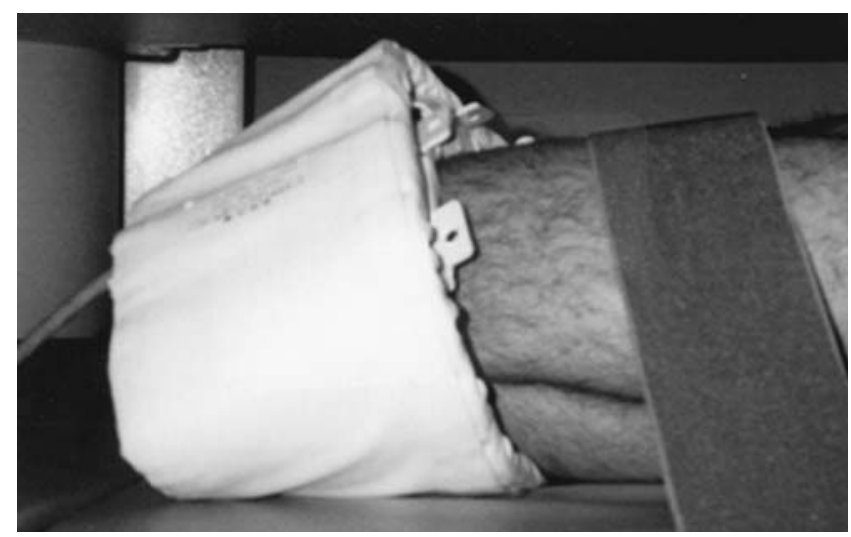

Fig. 1

Scanning position at passive maximum flexion 
$1200 \quad$ S. NAKAGAWA, Y. KADOYA, S. TODO, A. KOBAYASHI, H. SAKAMOTO, M. A. R. FREEMAN, Y. YAMANO

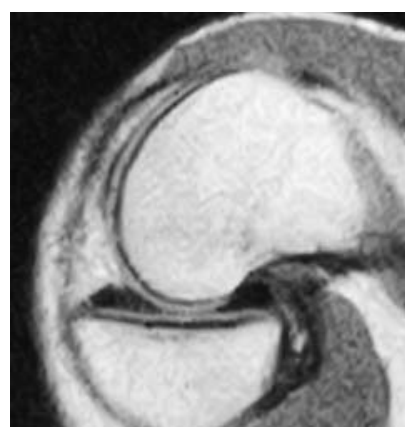

Fig. 2a

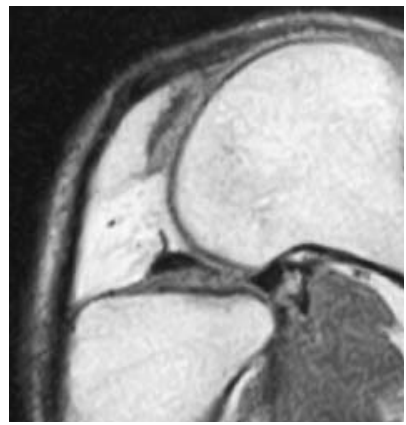

Fig. 2c

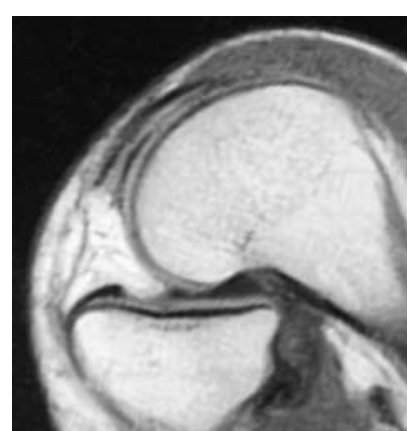

Fig. 2b

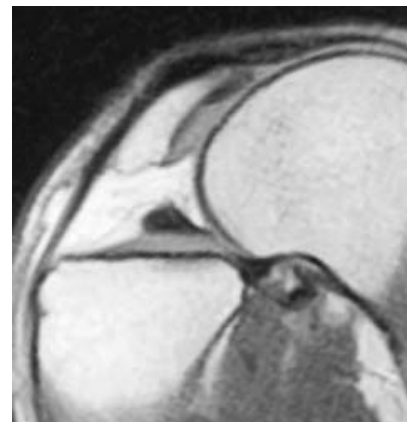

Fig. 2d

Representative MR images of medial and lateral compartments: $a$ and $b$, medial; c and d, lateral. Left column, active maximum flexion; right column, passive maximum flexion. Note that at passive maximum flexion the lateral femoral condyle articulates with the tibial popliteal facet while the medial condyle has moved back relatively little.

condyle rolls back especially after $60^{\circ}$. We have now shown that this process continues with further flexion so that by full passive flexion $\left(162^{\circ}\right)$ the lateral femoral condyle has moved back $28 \mathrm{~mm}$ (compared with its position at $90^{\circ}$ ) and has lost normal contact with the tibia. By contrast, the medial femoral condyle does not move back until $110^{\circ}$ in the Caucasian knee and then by $1 \mathrm{~mm}$ to $120^{\circ}{ }^{3}$ In the Japanese knee, medial movement may start at $90^{\circ}$ but amounts to only $2.0 \mathrm{~mm}$ by $133^{\circ}$ and a further $4.5 \mathrm{~mm}$ from $133^{\circ}$ to $162^{\circ}$. Thus, forced flexion of the Japanese knee from $90^{\circ}$ to $162^{\circ}$ is accompanied by about $28^{\circ}$ of tibial internal rotation and about $4.0 \mathrm{~mm}$ of femoral posterior translation towards full flexion.

At full passive flexion the lateral femoral condyle may be regarded as being posteriorly subluxed. The medial condyle still lies over the tibia but lifts away from it.

We thank Y. Ohara and M. Ito (Hitachi, Osaka, Japan) for their technical assistance in MRI. This work was partly funded with Research Promotion Fund by the Department of Orthopaedic Surgery, Osaka City University Medical School.

No benefits in any form have been received or will be received from a commercial party related directly or indirectly to the subject of this article.

\section{References}

1. Todo S, Kadoya Y, Moilanen T, et al. Anteroposterior and rotational movement of the femur during knee flexion. Clin Orthop 1999;362:162-70.

2. Hill PF, Vedi V, Williams A, et al. Tibiofemoral movement 2: the loaded and unloaded living knee studied by MRI. J Bone Joint Surg [Br] 2000;82-B:1196-8.

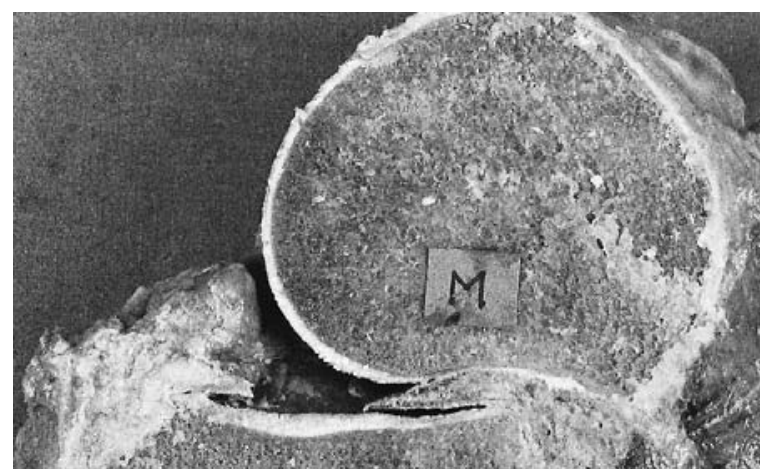

Fig. 3a

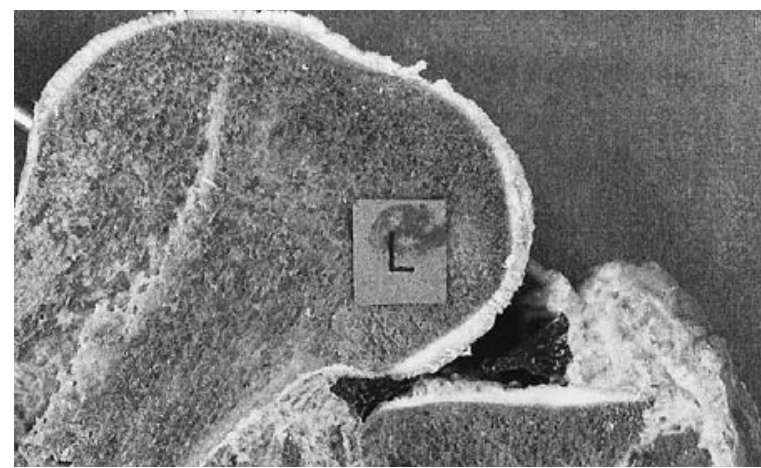

Fig. 3b

Cryosections of a Caucasian knee (quadriceps divided, obtained in Prague): a) medial; b) lateral. Note that the tibia and femur have lost contact and appear to be 'hinging' on the posterior horns of the menisci.

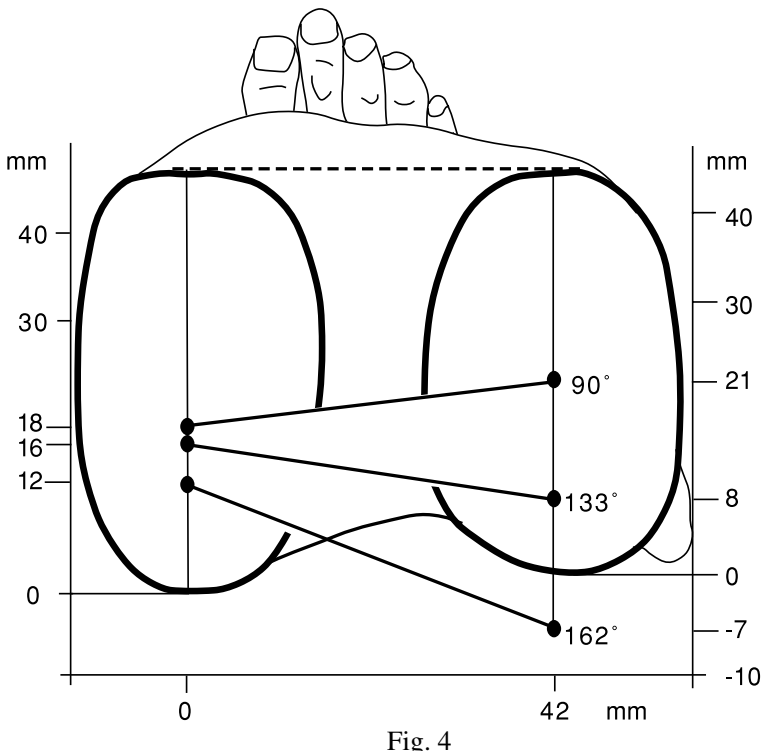

Diagram to show the positions of the FFCs at $90^{\circ}, 133^{\circ}$ (full active flexion) and $162^{\circ}$ (full passive flexion). A full description of diagrams of this type is in Iwaki et al.

3. Iwaki H, Pinskerova V, Freeman MAR. Tibiofemoral movement 1: the shapes and relative movements of the femur and tibia in the unloaded cadaver knee. J Bone Joint Surg [Br] 2000;82-B:1189-95.

A list of consulted publications concerning the normal knee will be found on the Journal of Bone and Joint Surgery web site (www.jbjs.org.uk) for this issue until 2002. 